\title{
Fractionated Coptis chinensis Extract and Its Bioactive Component Suppress Propionibacterium acnes-Stimulated Inflammation in Human Keratinocytes ${ }^{\text {S }}$
}

\author{
Jin Wook Lee ${ }^{1}$, Yoon Joong Kang ${ }^{1}$, Hyun Kyung $\mathrm{Choi}^{2 *}$, and Young Geol Yoon ${ }^{1 *}$ \\ ${ }^{1}$ Department of Biomedical Science, Jungwon University, Geosan 28024, Republic of Korea \\ ${ }^{2}$ Department of Medicinal Chemistry, Jungwon University, Geosan 28024, Republic of Korea
}

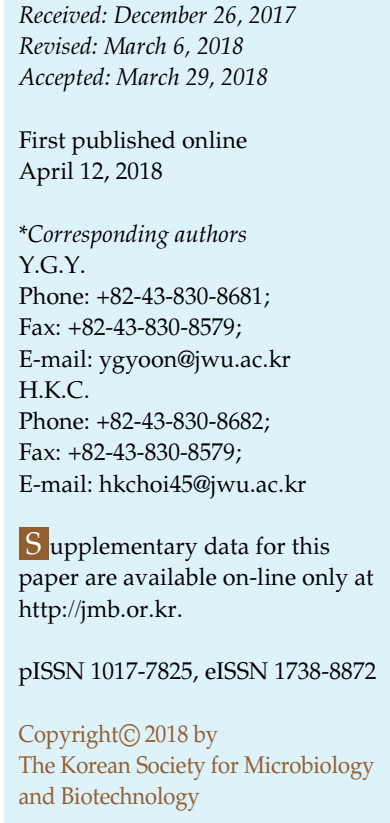

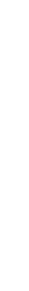


supplement for some food products and beverages because of its strong antibacterial and antioxidant activities [8,9]. CC contains high levels of diverse alkaloid compounds, including berberine, palmatine, jatrorrhizine, magnoflorine, epiberberine, and coptisine [10]. Among these, berberine has been confirmed as the main active component, and the berberine level is often used as a criterion in the quality control of huang lian products [7-9].

Impressively, the anti-inflammatory activities of berberine have been assessed in recent studies [10]. Berberine suppresses inflammation through complex mechanisms that involve MAPK signaling inhibition [11]. MAPKs are involved in regulating inflammatory mediators such as ERK, JNK, and p38 protein kinases at the transcriptional and translational levels; therefore, they have been potential therapeutic targets for the anti-inflammatory response in various studies [12]. In addition, berberine plays a crucial role in regulating the inflammatory response by inhibiting $\mathrm{NF}-\kappa \mathrm{B}$ and transcription factor activator protein 1 (AP-1) binding [13]. AP-1 is a key factor in inflammation and carcinogenesis. Berberine significantly inhibits the binding of AP-1 and NF- $\mathrm{KB}$ in a concentration- and time-dependent manner, potentially suppressing the activation of the transcription factor. Although the anti-inflammatory effects of the CC extracts and berberine have been investigated in many cells, their anti-inflammatory activity in the keratinocytic cells where inflammatory responses are induced by $P$. acnes have not been comprehensively studied.

Here, we explored the therapeutic potential of fractionated CC extracts and berberine, which is its main bioactive component, to regulate the production of inflammatory mediators in P. acnes-stimulated HaCaT keratinocytic cells. The inhibitory mechanisms of the inflammatory reaction were also assessed in these cells.

\section{Materials and Methods}

\section{Materials}

Berberine chloride (PHR1502), Griess reagent, and Methylthiazolyldiphenyl-tetrazolium bromide (MTT) were obtained from Sigma-Aldrich (USA). The antibodies used in the experiments were obtained from Abcam (USA) and Cell Signaling Technology (USA).

\section{Preparation and Isolation of Extracts}

Dried roots of $C$. chinensis Franch were purchased from the Kyungdong marketplace (Korea). Extracts were obtained from the roots by mixing ground root powder with $70 \%$ ethanol $(\mathrm{EtOH})$ $(1: 20(\mathrm{w} / \mathrm{v}))$ and keeping it at room temperature for $24 \mathrm{~h}$, repeating this once. The extracted solutions were evaporated to yield crude EtOH extracts. Five fractions were separated on the basis of polarity by mixing the crude $\mathrm{EtOH}$ extracts sequentially with $200 \mathrm{ml}$ of hexane, methylene chloride, ethyl acetate, and tertbutanol, each three times. The extracted organic layers for each solvent were combined and concentrated. The remaining aqueous layer was retained for further use.

\section{Single Compound Analysis}

The molecular mass of each single compound was analyzed using a quadrupole/time-of-flight mass spectrometer equipped with an electrospray ion source (Waters, USA). The instrument was adjusted using sodium fluoride solution. After dissolving in $100 \% \mathrm{MeOH}$, the sample was introduced by direct infusion into the ion source operating in positive mode at a $20 \mu \mathrm{l} / \mathrm{min}$ flow rate. All spectra were acquired over a $50-1,500 \mathrm{~m} / \mathrm{z}$ range. Leucine enkephalin was employed as the lock mass for the exact mass measurement correction.

\section{Cell Culture and Cytotoxicity}

$P$. acnes 3320 was purchased from the Korean Collection for Type Cultures (Korea) and cultured in reinforced clostridial medium (Difco, USA) under anaerobic conditions using a BBL Gas-Pak system (Becton Dickinson Microbiology Systems, USA). CRL-2309 were obtained from the American Tissue Culture Collection (USA) and cultured in DMEM with $10 \%$ heat-inactivated fetal bovine serum, penicillin $(100 \mathrm{U} / \mathrm{ml})$, and streptomycin $(100 \mathrm{mg} / \mathrm{ml})$ at $37^{\circ} \mathrm{C}$ in a humidified atmosphere with $5 \% \mathrm{CO}_{2}$. The cytotoxicities of the fractionated $\mathrm{CC}$ extracts and berberine were measured by MTT assay.

\section{Reverse-Transcription PCR}

Total RNA was prepared using Trizol reagent (Thermo Scientific, USA), and RNA ( $1 \mu \mathrm{g})$ was reverse-transcribed into cDNA using a reverse-transcription (RT)-PCR premix kit (iNtRON, Korea). PCR analysis was then performed using gene-specific primers. The primer sequences used for TNF- $\alpha$, IL-1 $\beta$, IL- 8 , and GAPDH were as follows: TNF- $\alpha, 5^{\prime}$-GGCAGTCAGATCATCTTCTCGAA- $3^{\prime}$ and 5'-GAAGGCCTAAGGTCCACTTGTGT-3'; IL-1 $\beta$, 5'-CATGAGCAC CTT CTT TTCCT-3' and 5'-TGTACCAGTTGGGGAACTCT-3'; IL-8, 5'-TTTGATACTCCCAGTCTTG-3' and 5'-GTTCTAACTCATTAT TCCGTAA-3'; GAPDH, 5'-AGGGCTGCTTTTAACTCTGGT-3' and 5'-CCCCACTTGATTTTGGAGGGA-3'.

\section{Enzyme-Linked Immunosorbent Assay}

HaCaT keratinocytic cells were plated at $1 \times 10^{5}$ cells/well in 12-well plates and cultured overnight. The cells were pretreated with CC extracts or berberine for $1 \mathrm{~h}$ and then $P$. acnes was added. After incubating the cells in a humidified incubator with $5 \% \mathrm{CO}_{2}$ at $37^{\circ} \mathrm{C}$ for $24 \mathrm{~h}$, the cell-cultured supernatant was harvested for enzyme-linked immunosorbent assay (ELISA) using a human inflammatory cytokine ELISA kit (BioLegend, USA). Absorbance was measured at $450-540 \mathrm{~nm}$ using a microplate reader.

\section{Western Blot Analysis}

HaCaT keratinocytic cells were plated at $1 \times 10^{5}$ cells/well in 
12-well plates and cultured overnight. The cells were then pretreated with CC extracts or berberine for $1 \mathrm{~h}$. After stimulating the cells with $P$. acnes for $24 \mathrm{~h}$, total cellular proteins were prepared using PBS lysis buffer. These proteins were separated using 10\% SDS-PAGE and transferred to PVDF membranes. These membranes were then blocked and incubated with a primary antibody overnight in a shaker at $4^{\circ} \mathrm{C}$. After washing three times with TBST, the membranes were incubated for $1 \mathrm{~h}$ with a horseradish peroxidase-conjugated secondary antibody. Protein bands were detected using an ECL kit (Biosesang, Korea) and ChemiDoc system (Bio-Rad, USA). All experiments were repeated three times and the most obvious results are presented.

\section{Immunofluorescence}

After the $P$. acnes-stimulated cells were treated with the CC extracts or berberine, they were fixed with $4 \%$ paraformaldehyde in PBS for $15 \mathrm{~min}$ and permeabilized with $0.25 \%$ Trixon X-100 for $15 \mathrm{~min}$. They were then incubated overnight with the primary NF$\kappa B$ p65 antibody at $4{ }^{\circ} \mathrm{C}$. The cells were washed three times in PBS, incubated overnight with biotin-conjugated secondary antibodies (Vector Labs, USA), and then incubated with Cy2-streptavidin (GE Healthcare, USA) overnight at $4^{\circ} \mathrm{C}$. The nuclei were counterstained using Hoechst 33258 (Invitrogen, USA) for $5 \mathrm{~min}$. The prepared cells were then observed using a fluorescence microscope and images were recorded.

\section{Statistical Analysis}

All experiments were repeated three times and the results expressed as the mean $\pm \mathrm{SD}$. Differences in results were tested for statistical significance using Student's $t$-tests. A $p$ value of $<0.05$ was considered significant.

\section{Results}

\section{Cytotoxicity and Antibacterial Activity of the Five Extracted Fractions}

The in vitro cytotoxicity of the five fractions was tested
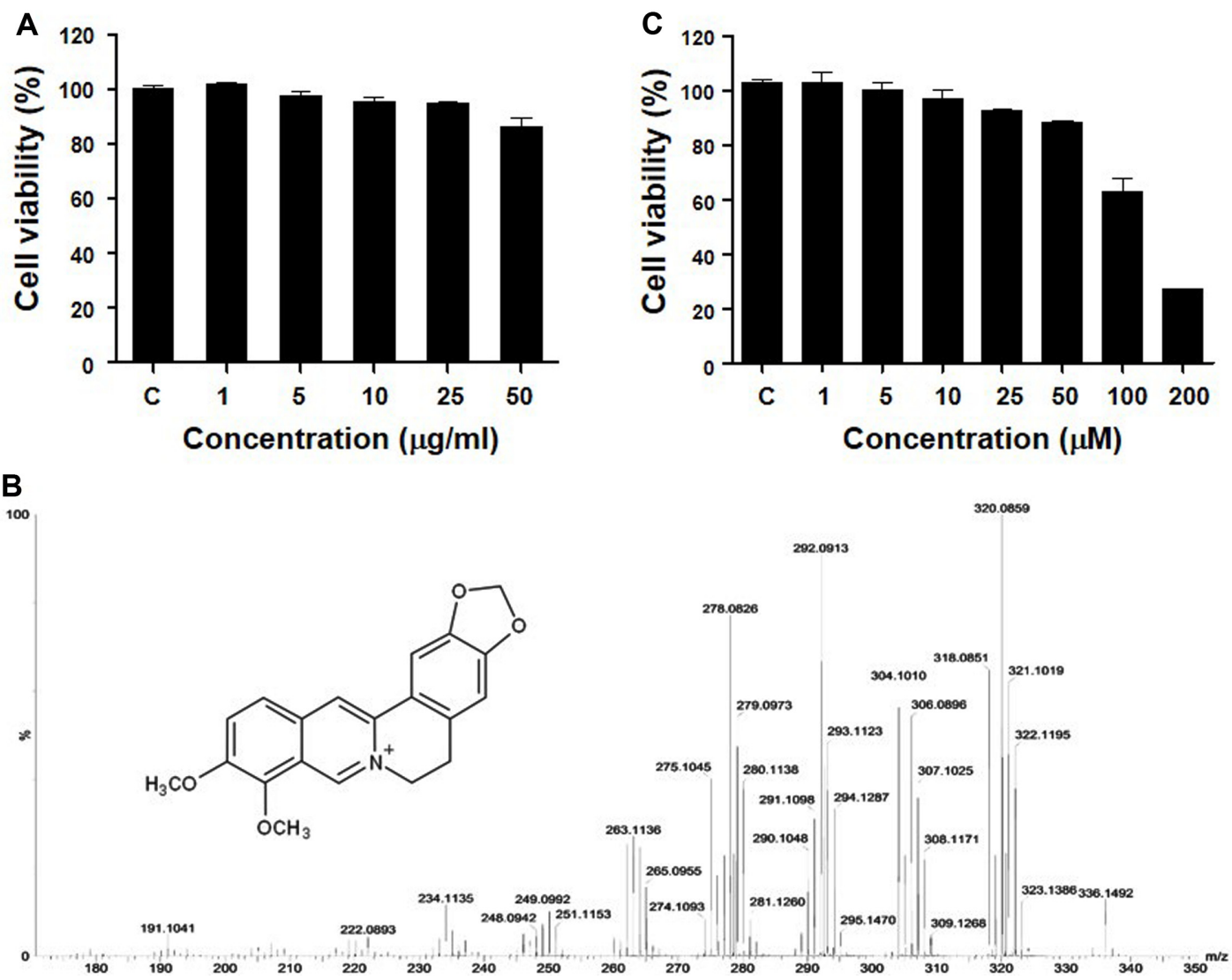

Fig. 1. In vitro cytotoxicity and compound analyses.

(A) Viability of HaCaT keratinocytic cells after treatment with the aqueous fraction from Coptis chinensis (CCW). The cells were treated with the indicated concentrations $(0,1,5,10,25$, and $50 \mu \mathrm{g} / \mathrm{ml})$ for $24 \mathrm{~h}$. (B) Compound analysis by mass spectrometry. Berberine was confirmed as a single major compound in the CCW fraction separated from the C. chinensis extracts. (C) Viability of HaCaT cells after treatment with berberine. The cells were treated with the indicated concentrations $(0,1,5,10,25,50,100$, and $200 \mu \mathrm{M})$ for $24 \mathrm{~h}$. Cell viability was evaluated using the tetrazolium MTT assay. The data represent the mean $\pm \mathrm{SD}$ of three independent experiments. $\mathrm{C}$, control. 
using the MTT assay method (Figs. 1A and S1). The treatment of each fraction indicated differential cell viability. The hexane, methylene chloride, ethyl acetate, and tert-butanol fractions exhibited apparent cytotoxicity at concentrations of $1-10 \mu \mathrm{g} / \mathrm{ml}$ (Fig. S1). In contrast, the aqueous fraction of CC (CCW) showed no cytotoxicity in the cells at concentrations up to $50 \mu \mathrm{g} / \mathrm{ml}$ (Fig. 1A). Because some bacterial strains have been reported to induce an inflammatory response and diseases in infected cells [14], we explored the antibacterial activity of the five fractions by applying them to microorganisms easily found on human skin and in contaminated environments (P.acnes, Staphylococcus aureus, and Listeria monocytogenes) and measuring their minimum inhibitory concentrations. The aqueous, ethyl acetate, and hexane fractions showed strong antibacterial activities against all three microorganisms, with minimum inhibitory concentrations in the range of 0.5-1 $\mu \mathrm{g} / \mathrm{ml}$ (Table S1). Because the CCW fraction showed strong antibacterial activity against $P$. acnes but no sign of cytotoxicity in HaCaT cells (Table S1 and Fig. 1A), we decided to use this fraction to evaluate the anti-inflammatory function by assaying the inhibition of P.acnes-induced inflammation in HaCaT keratinocytic cells.

\section{Berberine Isolated from the CCW Fraction}

We performed a compound analysis of the CCW fraction to identify the key bioactive components responsible for its strong antibacterial and anti-inflammatory functions. Tandem mass spectrometry analysis verified one of the components as a single compound (Fig. 1B), with a molecular weight of $\mathrm{m} / \mathrm{z} 336.1492$; this exactly matched that of berberine's structure. The fragment ions seen in the spectrum (Fig. 1B) with $\mathrm{m} / \mathrm{z} 320.08,306.09$, and 290.10 were owing to the 1,3-dioxolane ring structure, and the peak of $\mathrm{m} / \mathrm{z} 320.08$ originated from the elimination of a single oxygen from the ring structure. The peaks of $\mathrm{m} / \mathrm{z} 306.09$ and 290.10 were derived from the breakage of $-\mathrm{CH}_{2} \mathrm{O}$ - and $-\mathrm{OCH}_{2} \mathrm{O}$ - ring structures, respectively, and the fragment ion with $\mathrm{m} / \mathrm{z} 274.11$ was produced by the elimination of the dimethoxy group from berberine. This confirmed that berberine was a major single compound of the CCW fraction.

We tested the in vitro cytotoxicity of berberine using HaCaT keratinocytic cells (Fig. 1C). Various concentrations of berberine $(1,5,10,25,50,100$, and $200 \mu \mathrm{M})$ were used to treat the cells for $24 \mathrm{~h}$. Berberine exhibited low cytotoxicity to these cells at concentrations between 1 and $50 \mu \mathrm{M}$ (Fig. 1B). We therefore decided to use berberine at concentrations of 25 and $50 \mu \mathrm{M}$ for further experiments.

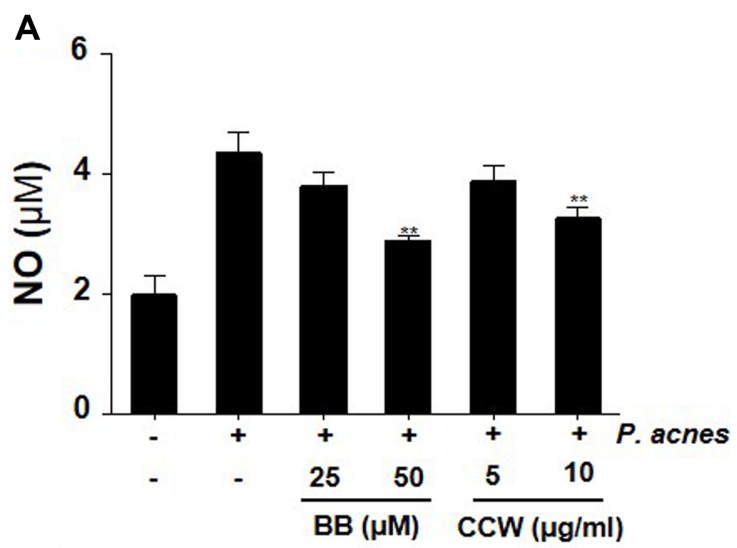

B

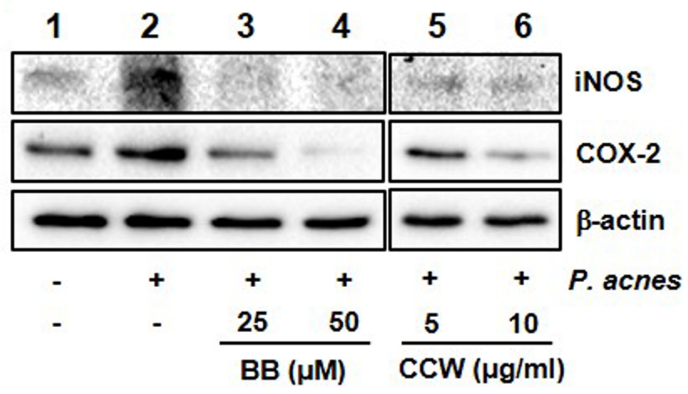

Fig. 2. Effects of the $C$. chinensis aqueous fraction (CCW) and berberine on the Propionibacterium acnes-stimulated production of nitric oxide and expression of inducible nitric oxide synthase and cyclooxygenase in $\mathrm{HaCaT}$ keratinocytic cells.

(A) Nitric oxide (NO) production assay. The cells pretreated with berberine (BB) $(25$ and $50 \mu \mathrm{M})$ and the CCW fraction $(5$ and $10 \mu \mathrm{g} / \mathrm{ml})$ were infected with heat-killed P. acnes $(50 \mu \mathrm{g} / \mathrm{ml})$ for $24 \mathrm{~h}$. Production of NO was measured with Griess reagent. The results were obtained from three independent experiments. ${ }^{* *} p<0.01$ compared with the cells treated with heat-killed $P$. acnes. (B) Western blot analysis of inducible nitric oxide synthase (iNOS) and cyclooxygenase (COX-2) expression. The expression levels of iNOS and COX-2 in P. acnestreated cells were reduced in a concentration-dependent manner by pretreatment with $\mathrm{BB}$ and the $\mathrm{CCW}$ fraction.

Effects of the CCW Fraction and Berberine on the P. acnesInduced Production of Nitric Oxide and the Expression of Inducible Nitric Oxide Synthase and Cyclooxygenase

To identify the anti-inflammatory activity of the CCW fraction and berberine, we first investigated whether it inhibited the production of nitric oxide (NO) and the expression of inducible nitric oxide synthase (iNOS) and cyclooxygenase (COX-2) in $P$. acnes-induced HaCaT keratinocytic cells. Treating the cells with P. acnes significantly enhanced the production and expression of NO and iNOS (Fig. 2). However, pretreatment of these cells with the CCW fraction and berberine clearly suppressed both NO 
production and iNOS expression (Figs. 2A and 2B, respectively). In particular, berberine at a concentration of $50 \mu \mathrm{M}$ significantly reduced NO production to approximately $66 \%$ of that in the P.acnes-stimulated cells, which is in good agreement with a previous report using RAW264.7 cells [15] (Fig. 2A). In addition, the iNOS protein expression decreased with treatment of the CCW fraction and berberine (Fig. 2B). When HaCaT kerationocytic cells were infected with heat-killed $P$. acnes, the iNOS protein expression was clearly increased compared with the untreated control (Fig. 2B, lanes 1 and 2). Although the iNOS protein bands were vaguely detected with treatment of 25 and $50 \mu \mathrm{M}$ berberine owing to the band spread in the gel, it was evident that the iNOS expression tended to decrease drastically in a dose-dependent manner with the pretreatment of berberine and the CCW fraction (Fig. 2B, lanes 3-6). When COX-2 expression was investigated by western blot analysis, we found that treatment with the CCW fraction and berberine apparently inhibited it in a concentrationdependent manner (Fig. 2B). These results indicated that the suppressive effect of the $\mathrm{CCW}$ fraction and berberine on NO production may be associated with their strong inhibitory activity on iNOS and COX-2 expression in HaCaT keratinocytic cells.

Effects of the CCW Fraction and Berberine on the Production of Cytokines in P. acnes-Stimulated Keratinocytic Cells

The inflammatory response in a cell is accompanied by the expression of cytokines with a variety of inflammatory mediators [16]. It has been reported that P. acnes triggers the expression of proinflammatory cytokines and chemokines and that it is one of the major pathogenic factors leading to the onset and worsening of diseases involving inflammation around the hair follicle and sebaceous glands [17]. We therefore examined whether treatment with P. acnes could elicit inflammatory responses in keratinocytes, using ELISA and RT-PCR to confirm the expression levels of inflammatory cytokines IL- $1 \beta$, IL- 8 , and TNF- $\alpha$. Incubation of $\mathrm{HaCaT}$ keratinocytic cells with heat-killed P.acnes augmented the expression levels of these cytokines (Fig. 3), but treatment of these $P$. acnes-stimulated cells with the CCW fraction significantly inhibited their expression in a concentration-dependent manner (Fig. 3A). The expression levels of mRNA of these inflammatory cytokines were also reduced, indicating that the CCW fraction contained components that suppressed the P.acnes-induced inflammatory response in these keratinocytic cells (Fig. 3C).

We also assayed the production of TNF- $\alpha$, IL-1 $\beta$, and IL-8 by ELISA to determine the effects of berberine on the production of these proinflammatory cytokines and chemokine. The levels of expression of TNF- $\alpha$, IL- $1 \beta$, and IL-8 were markedly enhanced in the $P$. acnes-stimulated cells compared with the untreated control cells (Fig. 3B). However, when the $P$. acnes-stimulated cells were pretreated with berberine, the production of TNF- $\alpha$, IL-1 $\beta$, and IL- 8 was significantly inhibited in a concentration-dependent manner (Fig. 3B). In particular, $50 \mu \mathrm{M}$ berberine prominently inhibited the production of TNF- $\alpha$ in the P. acnes-stimulated HaCaT keratinocytic cells. The levels of mRNA expression of these inflammatory cytokines also decreased, indicating that berberine from the CCW fraction was one of the components that suppressed the P. acnes-induced inflammatory response in the HaCaT keratinocytic cells (Fig. 3D).

\section{Effects of the CCW Fraction and Berberine on MAPK} Signals in the P. acnes-Stimulated Keratinocytic Cells

Because modulation of the inflammatory response is commonly associated with activation of MAPK signaling proteins [18], we explored the effect of the CCW fraction and berberine on MAPK signals in the P. acnes-stimulated HaCaT keratinocytic cells (Fig. 4A). The phosphorylation of ERK, JNK, and p38 kinases in these keratinocytic cells was significantly augmented with the treatment of heatkilled $P$. acnes, but this was markedly reduced when the cells were treated with the CCW fraction. In particular, the phosphorylation of ERK and p38 in the HaCaT keratinocytic cells was prominently suppressed with the CCW fraction at $10 \mu \mathrm{g} / \mathrm{ml}$ (Fig. 4A). Similarly, treatment with berberine clearly suppressed the $P$. acnes-induced phosphorylation of ERK, JNK, and p38, with the phosphorylation of JNK and p38 significantly inhibited by $50 \mu \mathrm{M}$ berberine (Fig. 4B). These results indicated that the CCW fraction and berberine exerted an anti-inflammatory effect via modulation of the MAPK signaling pathway.

Effects of the CCW Fraction and Berberine on NF- $\kappa B$ Signals in the $P$. acnes-Stimulated Keratinocytic Cells

NF- $\kappa \mathrm{B}$ p65 is a central transcription factor for the upregulation of several proinflammatory cytokine genes that mediate the inflammatory response [19]. We examined if the CCW fraction and berberine inhibited the expression

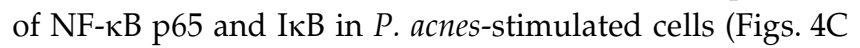
and $4 \mathrm{D})$. Because the NF- $\mathrm{B}$ p65 pathway is mainly modulated by phosphorylation of IкB $\alpha$ proteins, we investigated the levels of expression of phospho-IкB $\alpha$ and phospho-NF- $\kappa$ B p65 by western blotting after treatment with the CCW fraction at concentrations of 5 and $10 \mu \mathrm{g} / \mathrm{ml}$ 
A
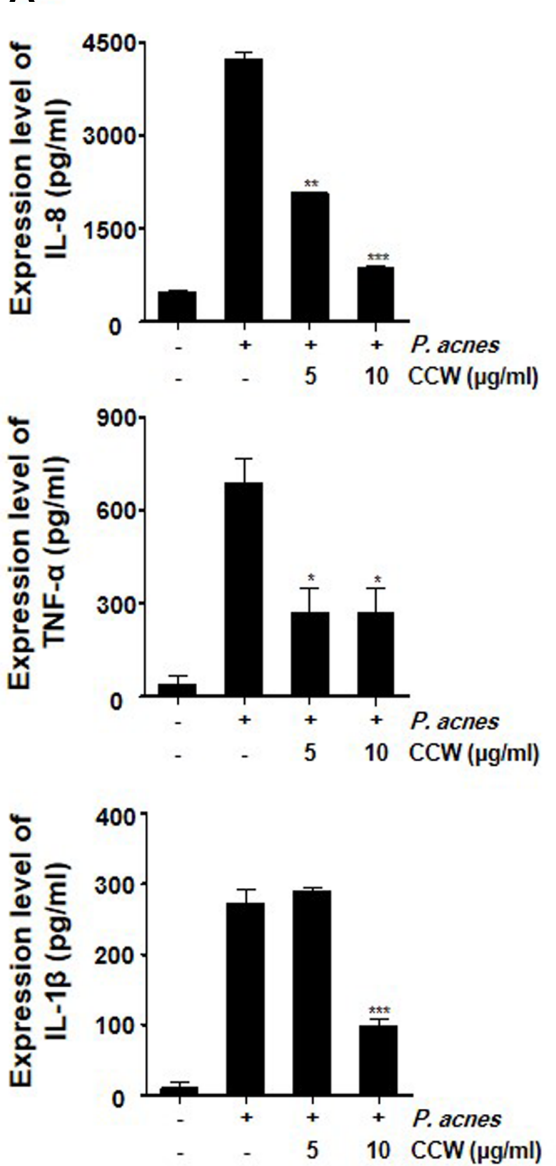

C

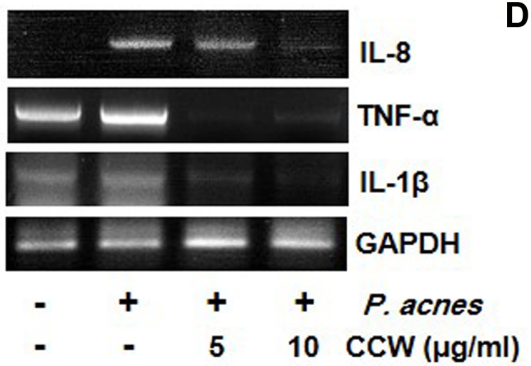

B
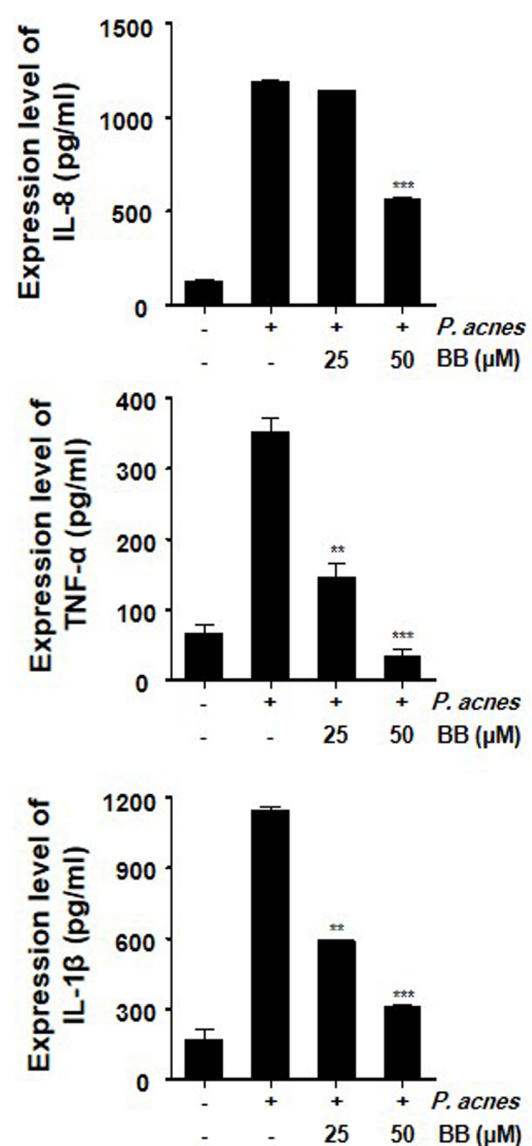

D

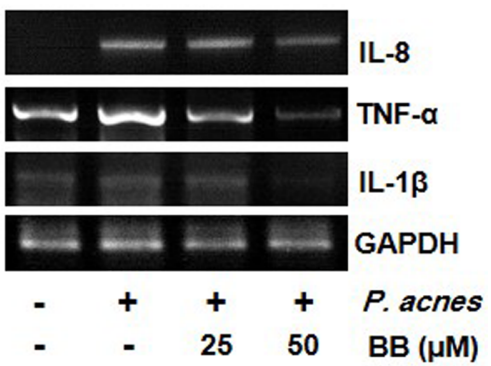

Fig. 3. Effects of the C. chinensis aqueous fraction (CCW) and berberine on the production of inflammatory cytokines in HaCaT keratinocytic cells.

(A) Production of tumor necrosis factor (TNF)- $\alpha$, interleukin (IL)-1 $\beta$, and IL-8 after treatment with the CCW fraction. The cells were pretreated with 5 and $10 \mu \mathrm{g} / \mathrm{ml}$ of the CCW fraction for $2 \mathrm{~h}$ and then stimulated with Propionibacterium acnes $(50 \mu \mathrm{g} / \mathrm{ml})$ for $24 \mathrm{~h}$. (B) Production of TNF- $\alpha$, IL-1 $\beta$, and IL-8 after treatment with berberine (BB). The cells were pretreated with 25 and $50 \mu \mathrm{M} \mathrm{BB}$ for $2 \mathrm{~h}$ and then stimulated with $P$. acnes (50 $\mu \mathrm{g} / \mathrm{ml})$ for $24 \mathrm{~h}$. Cytokine production in the culture medium was measured by enzyme-linked immunosorbent assay. The assay was conducted three times. ${ }^{* *} p<0.001,{ }^{* *} p<0.01$, and ${ }^{*} p<0.05$, compared with the cells treated with heat-killed P. acnes. (C and D) Reverse-transcription PCR analysis of the inflammatory cytokines after treatment with the CCW fraction (C) and BB (D). The cells were pretreated with $5 \mathrm{and} 10 \mu \mathrm{g} / \mathrm{ml}$ of the CCW fraction or 25 and $50 \mu \mathrm{M}$ of BB for $2 \mathrm{~h}$ and stimulated with P. acnes $(50 \mu \mathrm{g} / \mathrm{ml})$ for $24 \mathrm{~h}$. First-strand cDNA was prepared and PCR was then performed using the gene-specific primers for TNF- $\alpha$, IL-1, IL-8, and GAPDH.

(Fig. 4C). The expression of phosphorylated IкBa and NF-kB p65 was upregulated in these $\mathrm{HaCaT}$ keratinocytic cells in response to the $P$. acnes stimulation (Figs. 4C and 4D; lane 2), but this was markedly inhibited by treatment with the 
A

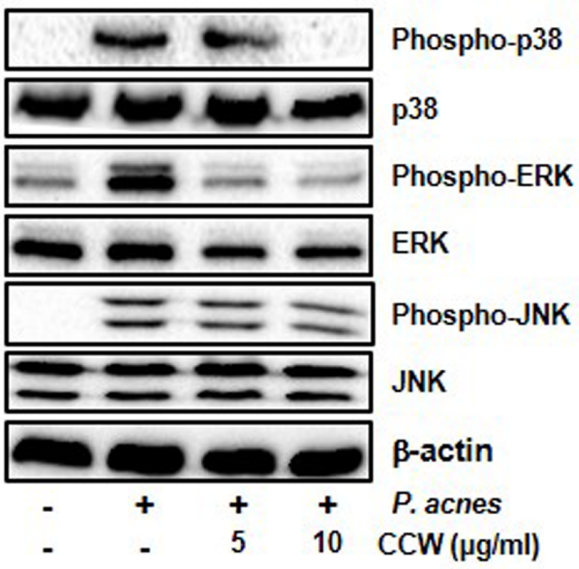

B

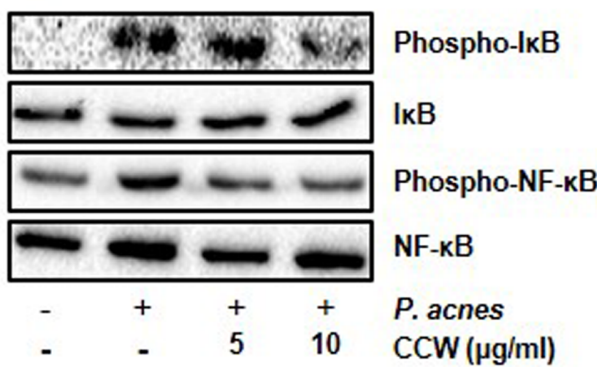

C

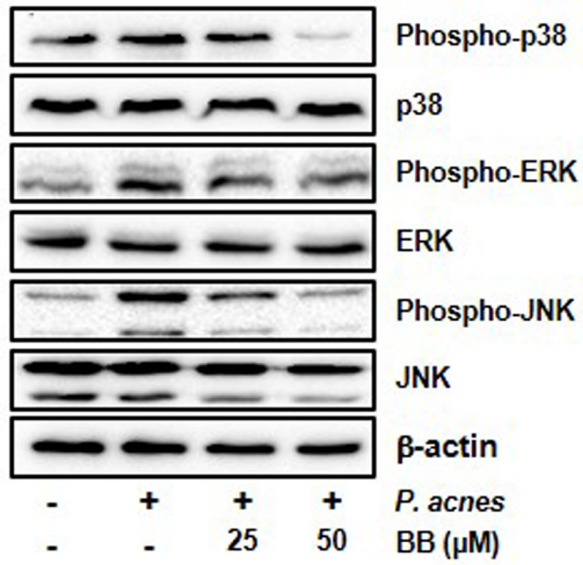

D

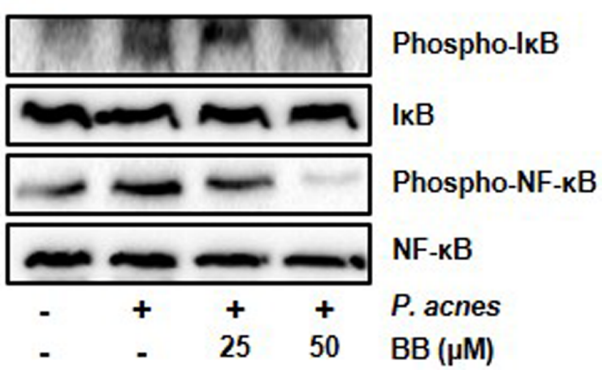

Fig. 4. The $C$. chinensis aqueous fraction (CCW) and berberine suppressed the mitogen-activated protein kinase (MAPK) and nuclear factor (NF)- $\mathrm{KB}$ signaling pathways in Propionibacterium acnes-stimulated HaCaT keratinocytic cells.

(A) Suppression of the MAPK signaling pathway by the CCW fraction. Cells were pretreated with the CCW fraction (5 and $10 \mu \mathrm{g} / \mathrm{ml})$ for $1 \mathrm{~h}$ and then stimulated with P. acnes $(50 \mu \mathrm{g} / \mathrm{ml})$ for $1 \mathrm{~h}$. The phosphorylation of MAPK was analyzed by western blotting. (B) Suppression of the NF- $\mathrm{kB}$ signaling pathway by the CCW fraction. The cells were prepared as for the MAPK pathway analysis. The phosphorylation of NF- $\mathrm{KB}$ was analyzed by western blot analysis. (C) Suppression of the MAPK signaling pathway by berberine (BB). Cells were pretreated with BB $(25$ and $50 \mu \mathrm{M})$ for $1 \mathrm{~h}$ and then stimulated with P. acnes $(50 \mu \mathrm{g} / \mathrm{ml})$ for $1 \mathrm{~h}$. (D) Suppression of the NF- $\mathrm{KB}$ signaling pathway by BB. Western blot analysis showed that phosphorylation of ERK, JNK, p38, IкB, and NFKB was inhibited by both the CCW fraction and BB in the P. acnes-stimulated HaCaT cells.

CCW fraction (Fig. 4C; lanes 3 and 4). In particular, the phosphorylation of IкBa was significantly suppressed by the $10 \mu \mathrm{g} / \mathrm{ml} \mathrm{CCW}$ fraction (Fig. 4C; lane 4). Similarly, pretreatment with berberine inhibited phosphorylation

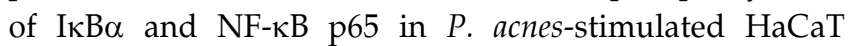
keratinocytic cells (Fig. 4D; lanes 3 and 4). In particular, the phosphorylation of NF- $\kappa$ B p 65 was significantly suppressed by $50 \mu \mathrm{M}$ berberine (Fig. 4D; lane 4 ).

The translocation of NF- $\mathrm{BB}$ p 65 to the nucleus can occur in TNF- $\alpha$-induced human keratinocytes [20]. We confirmed that this translocation occurred in $P$. acnes-stimulated HaCaT keratinocytic cells (Fig. 5B) and that it was notably impaired by treatment with the CCW fraction (Figs. 5C and $5 \mathrm{D})$, with the inhibition especially dramatic with $10 \mu \mathrm{g} / \mathrm{ml}$
CCW (Fig. 5D). Similarly, we also confirmed that treatment with berberine prohibited the nuclear translocation of NF- $\mathrm{KB}$ p65 in HaCaT keratinocytic cells (Figs. 5E and 5F), with remarkable inhibition by $50 \mu \mathrm{M}$ berberine. These results demonstrated that the CCW fraction and berberine inhibited $P$. acnes-induced expression and the nuclear translocation of NF-kB-related proteins. The inhibition of the NF- $\mathrm{BB}$ signaling pathway could result in the suppression of anti-inflammatory cytokines and inflammatory mediators, exerting anti-inflammatory activity.

\section{Discussion}

C. chinensis is often used as a traditional herbal medicine 


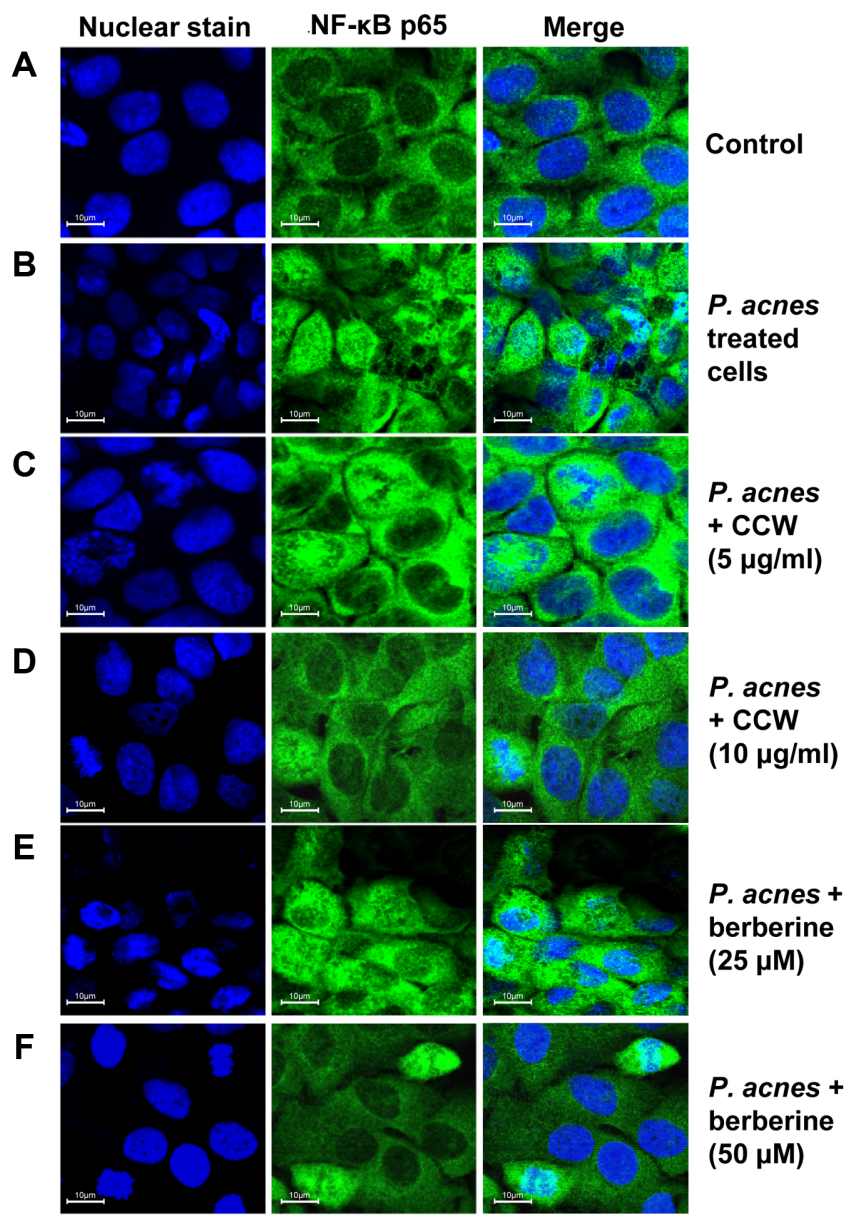

Fig. 5. Effects of the $C$. chinensis aqueous fraction $(\mathrm{CCW})$ and berberine on the translocation of nuclear factor (NF)- $\mathrm{KB}$ p65 in the P. acnes-stimulated HaCaT keratinocytic cells.

(A-F) Representative photomicrographs of NF-кB p65 (green) and nuclei stained with Hoechst 33258 (blue) in P. acnes-stimulated $\mathrm{HaCaT}$ keratinocytic cells. The cells were fixed and stained with NF- $\mathrm{KB}$ p65 monoclonal antibody and Hoechst nuclear stain. Without the treatment of $P$. acnes, NF- $\mathrm{KB}$ was predominately found in the cytoplasm (A), whereas with $P$. acnes stimulation, it translocated into the nucleus (B). The addition of the CCW fraction clearly inhibited the NF- $\mathrm{KB}$ translocation (C and $\mathbf{D}$ ), shown by there being hardly any nuclear p65 staining (D). Treatment with $25 \mu \mathrm{M}$ berberine had a slight inhibiting effect on NF- $\mathrm{KB}$ translocation, with some p65 staining observed in the nuclei (E). The addition of $50 \mu \mathrm{M}$ berberine clearly inhibited the NF-кB translocation, with hardly any nuclear p65 staining (F).

for therapeutic purposes because of its strong antiinflammatory activity [7]. Its alkaloid components berberine, palmatine, coptisine, epiberberine, and jatrorrhizine have been reported to be associated with its anti-inflammatory activity in immune cells [21]. However, their effectiveness

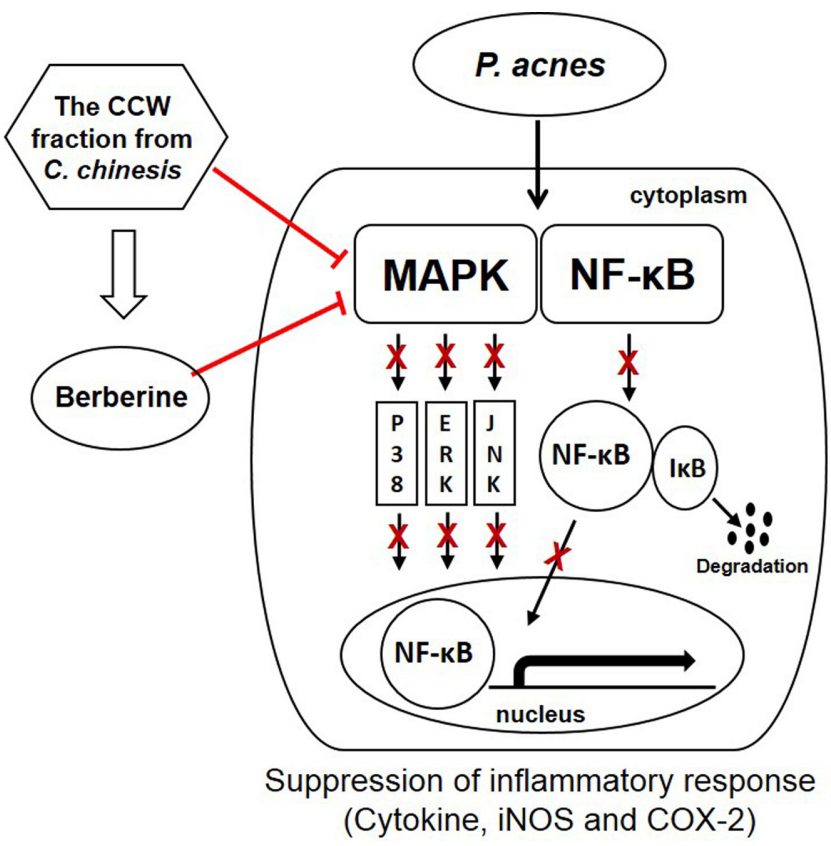

Fig. 6. Schematic diagram of the suppressive effect of the Coptis chinensis aqueous fraction (CCW) and berberine, its main component, on the inflammatory response via mitogenactivated protein kinase (MAPK) and nuclear factor (NF)-кB pathways in Propionibacterium acnes-stimulated HaCaT keratinocytic cells.

and the mechanisms underlying the anti-inflammatory effects on inflammatory skin diseases such as acne remain unknown. In this study, we investigated the therapeutic potential of the fractionated $\mathrm{CC}$ extract and of berberine, the main bioactive component of $\mathrm{CC}$, in relation to regulation of the production of proinflammatory cytokines, $\mathrm{NO}$, inflammatory proteins, and NF- $\mathrm{KB}$ p65 transcription factors in $\mathrm{HaCaT}$ keratinocytic cells stimulated by P. acnes.

Various studies have shown that $P$. acnes induces the expression of proinflammatory cytokines and chemokines, including TNF- $\alpha$, IL-1 $\beta$, IL-6, and IL- 8 , in keratinocytic cells $[14,17,22]$. Enhanced IL-8 expression was also observed in $P$. acnes-stimulated peripheral blood mononuclear cells in patients with acne vulgaris [22]. In this study, we verified that treatment of $P$. acnes-stimulated HaCaT cells with the CCW fraction or with berberine inhibited the expression of the proinflammatory cytokines TNF- $\alpha$, IL-1 $\beta$, and IL-8. We confirmed the anti-inflammatory activity of the CCW fraction and berberine by analyzing the levels of mRNA expression of the inflammatory cytokines; both the CCW fraction and berberine significantly reduced mRNA expression levels of TNF- $\alpha$, IL-1 $\beta$, and IL- 8 compared with the levels 
in P. acnes-induced cells. These results demonstrated that the CCW fraction and berberine play a crucial role in suppressing the inflammatory response in $\mathrm{HaCaT}$ keratinocytic cells that were stimulated by $P$. acnes, through modulating the expression of the inflammatory cytokines.

The MAPK pathway has been reported to play an important role in regulating the production of proinflammatory mediators in P. acnes-induced keratinocytes [14, 23]. Various extracellular stimuli, such as microbial infection, can activate the synthesis and secretion of MAPKs such as ERK, JNK, and p38 [12]. Activation of these components requires phosphorylation of unique amino acid sequences of MAPKs. The phosphorylated MAPKs can bind to other target kinases, translocate to the nucleus, and trigger the transcription of proinflammatory genes. In our study, phosphorylated ERK, JNK, and p38 increased significantly in the P. acnes-stimulated $\mathrm{HaCaT}$ keratinocytic cells, but these levels were clearly decreased in the cells treated with the CCW fraction and berberine. These results indicate that the CCW fraction and berberine employ the antiinflammatory response via fine regulation of the MAPK pathway by post-translational modifications to their components [24].

In addition, MAPKs regulate the transcription of iNOS, COX-2, and proinflammatory cytokines in various cells by activating the transcription factor NF- $\mathrm{kB}[23,25]$. The most prominent transcription factor of the NF- $\kappa B$ pathway is the NF- $\mathrm{BB}$ p50/p65 heterodimer [19]. In its inactivated normal condition, this cytoplasmic transcription factor is suppressed by binding with the inhibitor IкB $\alpha$ and remaining in the cytoplasm. When NF- $\kappa \mathrm{B}$ and MAP kinases are exposed to pathogens such as P.acnes and LPS, ІкB kinase phosphorylates the inhibitory I $\mathrm{I} B \alpha$ protein, resulting in

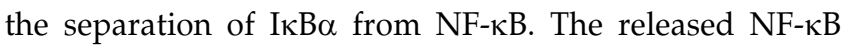
$\mathrm{p} 50 / \mathrm{p} 65$ is then transferred to the nucleus, where the transcription factors induce and express genes involved in inflammatory signal transduction [26]. In our experiments, the expression levels of phosphorylated I $\mathrm{I} B \alpha$ and NF- $\mathrm{\kappa B}$ increased in $\mathrm{HaCaT}$ keratinocytic cells that were exposed to $P$.acnes, with this increase dramatically suppressed by treatment with the $\mathrm{CCW}$ fraction and berberine. Furthermore, nuclear migration and the accumulation of NF- $\mathrm{kB}$ p 65 were considerably increased in the P.acnes-stimulated $\mathrm{HaCaT}$ keratinocytic cells but notably decreased after treatment with the CCW fraction and berberine. These results suggest that the $\mathrm{CCW}$ fraction and berberine effectively suppress P. acnes-induced inflammation by modulating NF- $\mathrm{kB}$ signaling proteins.

In conclusion, the CCW fraction from C. chinensis, and its main component berberine, showed potent anti-inflammatory activity by suppressing the production of $P$. acnes-mediated iNOS, NO, and inflammatory cytokines via inhibition of the NF-kB and MAPK activation pathways (Fig. 6). These results suggest the possibility of developing natural therapeutics using the CCW fraction and berberine to treat $P$. acnes-stimulated inflammatory skin diseases.

\section{Acknowledgments}

This study was supported by the National Research Foundation of Korea (NRF) Grant funded by the Korean government (NRF-2011-0008052 and 2015M3A6A8066204 to Yoon YG).

\section{Conflict of Interest}

The authors have no financial conflicts of interest to declare.

\section{References}

1. Omer H, McDowell A, Alexeyev OA. 2017. Understanding the role of Propionibacterium acnes in acne vulgaris: the critical importance of skin sampling methodologies. Clin. Dermatol. 35: 118-129.

2. Dessinioti C, Katsambas AD. 2010. The role of Propionibacterium acnes in acne pathogenesis: facts and controversies. Clin. Dermatol. 28: 2-7.

3. Farrar MD, Ingham E. 2004. Acne: inflammation. Clin. Dermatol. 22: 380-384.

4. Kim J, Ochoa MT, Krutzik SR, Takeuchi O, Uematsu S, Legaspi AJ, et al. 2002. Activation of Toll-like receptor 2 in acne triggers inflammatory cytokine responses. J. Immunol. 169: 1535-1541.

5. Kollisch G, Kalali BN, Voelcker V, Wallich R, Behrendt H, Ring J, et al. 2005. Various members of the Toll-like receptor family contribute to the innate immune response of human epidermal keratinocytes. Immunology 114: 531-541.

6. Grange PA, Raingeaud J, Calvez V, Dupin N. 2009. Nicotinamide inhibits Propionibacterium acnes-induced IL-8 production in keratinocytes through the NF- $\mathrm{KB}$ and MAPK pathways. J. Dermatol. Sci. 56: 106-112.

7. Kim JM, Jung HA, Choi JS, Lee NG. 2010. Identification of anti-inflammatory target genes of Rhizoma coptidis extract in lipopolysaccharide-stimulated RAW264.7 murine macrophagelike cells. J. Ethnopharmacol. 130: 354-362.

8. Teng H, Choi YH. 2014. Optimization of ultrasonic-assisted extraction of bioactive alkaloid compounds from rhizoma coptidis (Coptis chinensis Franch.) using response surface methodology. Food Chem. 142: 299-305. 
9. Yan D, Jin C, Xiao XH, Dong XP. 2008. Antimicrobial properties of berberines alkaloids in Coptis chinensis Franch by microcalorimetry. J. Biochem. Biophys. Methods 70: 845-849.

10. Zou K, Li Z, Zhang Y, Zhang HY, Li B, Zhu WL, et al. 2017. Advances in the study of berberine and its derivatives: a focus on anti-inflammatory and anti-tumor effects in the digestive system. Acta Pharmacol. Sin. 38: 157-167.

11. Jabbarzadeh Kaboli P, Rahmat A, Ismail P, Ling KH. 2014. Targets and mechanisms of berberine, a natural drug with potential to treat cancer with special focus on breast cancer. Eur. J. Pharmacol. 740: 584-595.

12. Roux PP, Blenis J. 2004. ERK and p38 MAPK-activated protein kinases: a family of protein kinases with diverse biological functions. Microbiol. Mol. Biol. Rev. 68: 320-344.

13. Remppis A, Bea F, Greten HJ, Buttler A, Wang H, Zhou Q, et al. 2010. Rhizoma coptidis inhibits LPS-induced MCP-1/ CCL2 production in murine macrophages via an AP-1 and NF-кB-dependent pathway. Mediators Inflamm. 2010: 194896.

14. Huang WC, Tsai TH, Chuang LT, Li YY, Zouboulis CC, Tsai PJ. 2014. Anti-bacterial and anti-inflammatory properties of capric acid against Propionibacterium acnes: a comparative study with lauric acid. J. Dermatol. Sci. 73: 232-240.

15. Wu J, Zhang H, Hu B, Yang L, Wang P, Wang F, et al. 2016. Coptisine from Coptis chinensis inhibits production of inflammatory mediators in lipopolysaccharide-stimulated RAW 264.7 murine macrophage cells. Eur. J. Pharmacol. 780: 106-114.

16. Turner MD, Nedjai B, Hurst T, Pennington DJ. 2014. Cytokines and chemokines: at the crossroads of cell signalling and inflammatory disease. Biochim. Biophys. Acta 1843: 25632582.

17. Nagy I, Pivarcsi A, Koreck A, Szell M, Urban E, Kemeny L. 2005. Distinct strains of Propionibacterium acnes induce selective human $\beta$-defensin- 2 and interleukin- 8 expression in human keratinocytes through Toll-like receptors. J. Invest. Dermatol. 124: 931-938.
18. Lee WR, Kim KH, An HJ, Kim JY, Chang YC, Chung H, et al. 2014. The protective effects of melittin on Propionibacterium acnes-induced inflammatory responses in vitro and in vivo. J. Invest. Dermatol. 134: 1922-1930.

19. Viatour P, Merville MP, Bours V, Chariot A. 2005. Phosphorylation of NF- $\kappa \mathrm{B}$ and $\mathrm{I} \kappa \mathrm{B}$ proteins: implications in cancer and inflammation. Trends Biochem. Sci. 30: 43-52.

20. Enk R, Ehehalt R, Graham JE, Bierhaus A, Remppis A, Greten HJ. 2007. Differential effect of Rhizoma coptidis and its main alkaloid compound berberine on TNF- $\alpha$ induced NFkB translocation in human keratinocytes. J. Ethnopharmacol. 109: $170-175$

21. Li JY, Wang XB, Luo JG, Kong LY. 2015. Seasonal variation of alkaloid contents and anti-inflammatory activity of Rhizoma coptidis based on fingerprints combined with chemometrics methods. J. Chromatogr. Sci. 53: 1131-1139.

22. Sugisaki H, Yamanaka K, Kakeda M, Kitagawa H, Tanaka K, Watanabe $\mathrm{K}$, et al. 2009. Increased interferon-g, interleukin12p40 and IL-8 production in Propionibacterium acnes-treated peripheral blood mononuclear cells from patient with acne vulgaris: host response but not bacterial species is the determinant factor of the disease. J. Dermatol. Sci. 55: 47-52.

23. Wang YY, Ryu AR, Jin S, Jeon YM, Lee MY. 2017. Chlorin e6-mediated photodynamic therapy suppresses $P$. acnesinduced inflammatory response via NFKB and MAPKs signaling pathway. PLoS One 12: e0170599.

24. Molina M, Cid VJ, Martin H. 2010. Fine regulation of Saccharomyces cerevisiae MAPK pathways by post-translational modifications. Yeast 27: 503-511.

25. Lee AY, Lee S, Kim HY, Lee S, Cho EJ. 2016. Anti-inflammatory effects of luteolin and luteoloside from Taraxacum coreanum in RAW264.7 macrophage cells. Appl. Biol. Chem. 59: 747-754.

26. Bonizzi G, Karin M. 2004. The two NF- $\kappa B$ activation pathways and their role in innate and adaptive immunity. Trends Immunol. 25: 280-288. 